XX.-Particulars of the construction of the Floating Bridge lately established across the Hamoaze, between Torpoint in the County of Cornwall, and Devomport in Devonshire. By JAMES M. RENDEL, M.Inst.C.E., \&c., \&c.

Introductory
remarks. lars of a work, new in all the arrangement of its details, if not in principle, and professing to be a valuable addition to the existing means of promoting internal communication, I deemed it necessary to submit to the delay of a few years, that experience might decide its pretensions to the countenance of a society formed for the promotion of practical information, and enrolling amongst its members most of the eminent engineers of the day.

I have also refrained from a published description of any kind, for besides the anxiety I have always felt that the invention should stand for just what it is really worth, I have from the beginning been desirous that its first public introduction should be made to this Institution.

It is now six years since the first floating bridge upon the principle of those I am about to describe, was established by me across the estuary of the Dart at Dartmouth, and four years have elapsed since the work delineated in the accompanying drawings, and more fully described in this paper, was established across the Hamoaze, between Torpoint and Devonport. From the want of experience, which is found almost always to limit the success of first efforts involving many new arrangements and adaptations of machinery, the success of the Dartmouth floating bridge was but partial; still it was sufficient to justify my undertaking the much more difficult work now about to be described, and to give my employers encouragement to entrust me with their confidence. The result, as I shall now proceed to shew, has been such as to be highly satisfactory to them, and consequently gratifying to myself.

Establishment of the Torpoint

In the year 1790, the Right Honourable the Earl of Mount ferry.

Edgecumbe, and Reginald Pole Carew, Esq., as owners of a large property in the neighbourhood of Devonport, obtained an Act of Parliament, which authorized them to establish a ferry across the Hamoaze, from Torpoint on the west or Cornwall side, to the Devonshire shore, a little to the north of 
Devonport, which town, then called Plymouth Dock, had become populous, and the mart for the produce of the opposite part of the county of Cornwall. The ferry accordingly became one of considerable traffic, and the accommodation it afforded, though limited to that derivable from common ferry boats, promoted buildings on the shores on either side, till at length, in 1829, several noblemen company formed
to establish astem-
boat similar to that and gentlemen of wealth and influence in the neighbourhood, assoto est similiar to that
bat Dundee, \&c. ciated themselves and subscribed a considerablecapital for improving the accommodation of the ferry, by establishing a twin steam boat upon the model of those then in use at Dundee. With this view, they became lessees of the ferry under a lease for 21 years. In less than two years their energy and anxiety for the accommodation of the public enabled them to make trial of this vessel, which, though built upon the Dundee model, both as regarded the machinery and boat, and executed under the most able professional advice, proved a complete failure. The tides were found too strong, and the line of passage too direct across the current, to enable the vessel to make her passages when there was either tide or wind to encounter.

This failure was the more discouraging from the liberality with which the work had been conducted, and the disappointment was great to the whole of the populous neighbourhood, which had expected from the establishment of this steam boat the means of easy transit for carriages, \&c., as well as for foot passengers.

Proposition for the

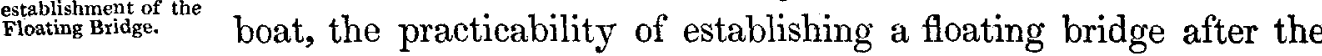

In the dilemma occasioned by the failure of the twin steammodel of that at Dartmouth, was made a subject of enquiry, and I was applied to as the author of that work. The greater width, depth, and current of the Hamoaze than of the Dart, were matters for anxious deliberation, before I could bring myself to report in favour of a trial. Besides which, the failure of a plan that was reported to have succeeded at the wider and more important ferry of Dundee, and the but partial success of the Dartmouth bridge, were, to a certain extent, discouraging circumstances; still I felt that the failure of the one, and the limited success of the other, proceeded from very obvious though opposite causes, the one growing out of inadaptation, the other from errors which more or less attend first efforts, or in other worcis from a want of experience.

After a very mature consideration, therefore, of all the circumstances of the two cases, I reported my opinion in favour of the practicability of establishing 
the floating bridge, which I shall proceed to describe, prefacing my narrative by some particulars of its site.

Particulars of the site of the Floating

Bridge.

The width of the river at the site of the bridge at high water is 2550 feet, and at low water 2110 feet. The greatest depth at high water is 96 feet, aud as spring tides rise 18 feet, the depth at low water is 78 feet. As will be seen by the section of the site in the plate, the greatest depth is at about $\frac{1}{3} \mathrm{~d}$ of the width from the west shore, the bottom on each side forming a tolerably regular curve to low-water mark. The strength of the current at ordinary spring tides, is from 260 feet per minute, or nearly three knots an hour, to 330 feet per minute, or $3 \frac{3}{4}$ knots an hour, varying in different parts of the line of passage, but heavy land floods, accompaned by a north-west wind, make the ebb tides run with a velocity of 430 feet per minute, or nearly 5 knots an hour; for which we had consequently to provide.

The site lies directly at right angles to the line of current, a disadvantage that could not be avoided, as the moorings of the ships of war prevented the selection of an oblique line of direction. As to the exposure of the site, I cannot better explain its degree than by stating that it is not uncommon for the ships lying in ordinary in the immediate vicinity of the bridge to drag their moorings. This has happened two or three times since the establishment of the floating bridge.

General description of the floating bridge

As will be seen on reference to Plates XX., XXI., and XXII.,

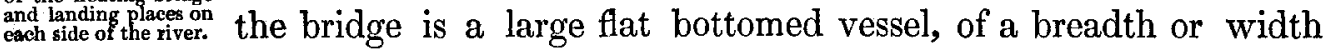
nearly equal to its length, divided in the direction of its length into three divisions, the middle being appropriated to the machinery which impels it, and each of the side divisions to carriages and traffic of all kinds. These side divisions or decks are raised from 2 feet to 2 feet 6 inches above the line of floatation, and by means of strong and commodious drawbridges or platforms, hung at each end of each deck, carriages drive on and off the deck from the landing place, embarking and disembarking thereby, without difficulty, or occasion for the least disturbance of horses or passengers, who remain in their places during the time of crossing the river. To make the passage certain and safe in any weather, and by night as well as by day, the bridge is guided by two chains, which, passing through it over cast iron wheels, are laid across the river and fastened to the opposite shores, consequently forming as it were a road, along which the bridge is made to travel forward and back from shore to shore as required; as will be better understood by a reference to Plate XIX. It will 
be seen on reference to Plate XXIII., that two small steam engines are employed as the moving power by turning a shaft, on each end of which there is a large cast iron wheel whereon the guide chains rest. The peripheries of these wheels are cast with sockets fitted to the links of the chain, so that when the wheels are stationary, the bridge is, as it were, moored by the chains, but when put in motion by the steam engines, it is moved in the reversed direction of, and the same velocity as the wheels. The landing places on each shore are simple inclined planes from low water mark to two feet above high water mark, formed to a slope or inclination of 1 in 12 or 1 in 14, and as the bridge approaches, the drawbridge is lowered on the plane; the draught of water of the bridge, and the projection of the drawbridge being such that carriages, \&c., are disembarked or embarked dry, or considerably above the water mark, whilst the bridge is all afloat, and out of danger of grounding or drifting, being held fast by the chains.

To prevent the chains being so tight as to interrupt the free navigation of the estuary, or to endanger their breaking, instead of being fastened or moored to the shores, their ends have heavy weights attached to them in shafts sunk at the head of each landing place, as shewn on Plate XIX. Of course these weights rise and fall as the strain upon the chains becomes more or less, and prevents the tension ever exceeding the balance weights, which are considerably below the weight to which the chains have been proved.

Details of the wood

plates XX., XXI.

The general elevation and plan shewn on Plate XX., and the and $X \mathbf{X} \times 1$.
and. bridge. The length, exclusive of the drawbridges, (which will be hereafter described,) is 55 feet, the width at midships 45 feet, and at the ends 38 feet 6 inches. The engine house and cabins are 14 feet 6 inches wide, and of the whole length of the bridge. The roadways or decks are 11 feet wide in the clear at the ends, and 12 feet 9 inches wide in the middle; 2 feet 3 inches above the load water line at the ends, and 3 feet in the middle by a camber arch of 9 inches to carry off the water. The draught of water, when the bridge is full of heavy carriages, is rather under 2 feet 6 inches, and the clear depth of hold 4 feet 3 inches; and as the engine house, \&c., rises 8 feet above the decks, the height from the hold to the roof is 12 feet 3 inches.

It will be observed from this description, and by a reference to the drawings, that the seat of the bridge in the water, or rather the line of floatation, is elliptic, and that the sides are curved vertically. (See Plate XXII.) The object 
of these forms is to relieve the bridge as much as possible from the effect of the current, and to prevent the sudden stoppage of a wave, and the consequent spray over the side.

To avoid unnecessary weight and draught of water, it was a matter of much importance to keep down the size of the scantling, as well as weight of the framing; yet from the great width and necessity for providing for occasional grounding, it was imperative to make the whole as stiff as possible. For the sake of lightness, all the planking and framing were of the best Quebec red pine, except those parts which formed the principal fastenings, including the two trussed frames along the bridge under the engine house partitions, and the diagonal braces or beams, which were of English oak, and iron kneed, and fastened with through bolts in the strongest manner. The engine house partitions, as well as the roof, are made moveable for the convenience of repairing or renewing the machinery. The roadways or decks have cross battens to prevent the horses' feet from sliding, and also for the better holding of a thin coat of sand and tar, as a more agreeable footing than wood. The fencing of the sides of the roadway is completed by carrying the timbers 3 feet 6 inches to 4 feet above the decks, and above that by the chains which suspend the drawbridges forming a rail.

Proof of the great strength of the fram.

In proof of the great strength of the framing of this bridge, I cannot do better than relate a circumstance which occurred to it. The shipwright who built the bridge, being desirous of exhibiting so great a novelty, invited a party of friends to witness the launch, which went off with great spirit and more wine than was sufficient for the christening. The wine in this, as in many other cases, caused its votaries to be altogether oblivious of such unimportant matters as time and tide, which as they "wait for no man," so in this instance they ebbed faster than was perceived. It was the business of the builder to place the bridge in the basin of the new victualling yard, but a short distance from where the bridge was launched. With proper caution, the width of the entrance had been measured, and found sufficient for the bridge, but the measurement was taken at high water. The batter of the pier heads of course narrowed the width of the entrance as the tide ebbed, so that when the bridge was brought to the basin, the entrance was found just too narrow, and being caught on a rapidly falling tide, the bridge was literally suspended between earth and heaven for 8 or 10 hours till the return tide. It happened, most fortunately, that the bridge was caught so nearly in the middle of its 
length that it balanced, otherwise it must have tipped endways and filled. I was not present at the accident, and concluded when I heard of it that, though not actually crushed, the framing must have suffered so much damage as to make a reconstruction necessary; but to my astonishment, as well as that of several ship builders whom I called in to aid me in the examination, nothing but a slight surface injury was observable, not a treenail having started or a fastening given way.

Since this the bridge has been frequently grounded, and found so stiff and stable, that it was not necessary to slacken a holding down bolt of the machinery.

Description of the drawbridges or plat-

forms.

The drawbridges or platforms are of the same width as the roadways or decks, to each end of which they are hung by strong eyes of wrought iron, and a turn bolt of $1 \frac{1}{2}$ inch diameter. Their length is 25 feet, they are fenced on each side by a strong trussed framing, and planked and battened, and sanded, to form a safe, level, and commodious communication between the landing place and the roadways of the bridge.

They are hung or suspended by two $\frac{3}{4}$ inch chains, one of which, as before stated, passes along the side of the bridge and forms a guard rail, and the other through the engine house, being there connected with a small purchase machine (shewn in Plate XXIII.). The chains, by passing over sheaves at the ends of the bridge and engine house, (as shewn,) and having their ends fastened to swivels attached to the sides of the drawbridges, not only suspend but also balance them, so that a very trifling power at the winch before named is sufficient to raise and lower them. When the bridge is in the act of crossing, the drawbridges form an angle with the water, as shewn by the general elevation at Plate XX., but of course, as the bridge approaches the landing places, the drawbridge by which the landing is to be made is lowered, and acts as a break to the machinery by its friction on the gravelled surface of the plane.

To obtain lightness, the scantling or framing of these platforms is Quebec red pine, planked with elm, the requisite strength being obtained by wrought iron suspension truss bars to each of the side pieces, as shewn on Plate XXI. These platforms are sufficiently strong to allow of the passage of a timber carriage of six tons' weight, which I have frequently witnessed, both fore and hind wheels being on the platform at the same time without causing the slightest derangement. 
Cross galleries or stages at the ends of the engine house and cabins.

Plates XX. and XXI.

To facilitate the passage from one roadway or deck to the other, there is a gallery or stage 6 feet 6 inches wide at the ends of the engine house or cabin, which forms an agreeable place for foot passengers, and the entrance to the cabin, where in rough weather shelter is obtained. These galleries are shewn in Plates XX. and XXI.

Cabin and engine house, boiler house, \&c., \&ce.

Plate XXIII.

At one end of the bridge is a spacious cabin, at the other end the boiler room, and between these is the engine room; all of which are shewn on the Plate. The roof is nearly flat, and covered with lead, 5 lbs. to the foot, laid on boarding fastened to a framing of wrought iron, which, as before stated, is made to take off easily. The side partitions of the engine and boiler rooms, and the framed pannelling which forms their external sides, are also made to shift easily, in case of repairs being wanted to the boilers or machinery.

Steam engines and machinery.

There are two steam engines, each having a cylinder of 19 Plate XXIII. inches diameter and 2 feet 6 inches stroke. They are common condensing steam engines, working at a pressure of $3 \frac{1}{2} \mathrm{lbs}$. per inch in the boiler, and at an average speed of 35 strokes per minute. There is but one boiler, the external form of which will be readily understood by a reference to Plate XXIII. It has four flues through it, the bottom or fire flue being the whole width of the boiler, less the watercourses, which are four inches, and the three others are ranged side by side, with watercourses all round them of four inches. This arrangement gives 65 feet of flue in the boiler, and the construction is found convenient and economical of fuel. The sides and ends of the boiler are cased or clothed with sawdust 6 inches thick, retained by pannelled boarding, moveable in rabbeted cast iron carriage pieces, screw tapped to the boiler.

As fresh water is easily obtained on the eastern landing place, I have found it advantageous to feed the boiler with it, and instead of taking the feeding water from the hot well, it is procured from a tank which is supplied once or twice a day by a hose from the pipes on the shore. The waste steam being thrown into this tank, is sufficient to raise the water to $100^{\circ}$. The tank and arrangement of the feed pumps, \&c., \&c., are fully shewn in Plate XXIII.

The condensing water is of course taken from the river.

The engines are coupled at right angles by a continuous crank shaft, one end of which carries the pinion which drives the chain wheels, and the other end carries a bevelled wheel for driving the fly wheel, which, though not 
necessary, is found to steady the working of the engines. This fly wheel, as will be seen by Plate XXIII., works horizontally under the roadway or deck of the bridge, where it was placed as being most out of the way, and is found to answer extremely well. The main pinion is 2 feet 10 inches diameter, and drives a wheel 7 feet 2 inches diameter, which is keyed on the shaft that carries the chain wheels. The chain wheels are 7 feet 6 inches diameter, keyed very firmly on the ends of a wrought iron shaft, which has its bearings on the tie beams of the bridge framing, and makes the distance between the wheels 10 feet 6 inches, and the distance from centre to centre of the two working or guide chains 11 feet. On the opposite side to the main gear wheel there is a break wheel of the same size, keyed to the shaft, which is furnished with a wrought iron clip or friction band. I have before stated that the periphery of each of the chain wheels is formed with cups gauged to the links of the chains, and that by this means the revolution of the wheels puts the bridge in motion in the opposite direction to the wheels, and as there can be no slipping of the chain, the velocity of the bridge is the same as that of the chain wheels, or about 320 feet per minute.

From this description it is evident that the periphery of the wheels will be liable to considerable wear by the weight and friction of the chains. This is provided for by casting the wearing parts in segments, and fixing new sets when necessary to the wheels.

The hand gear of the engines is managed in the most simple way, and the boiler so placed that one man can easily attend to the engines and fire. The signal for starting and stopping is given through speaking tubes, so placed that the conductor or deck-man can communicate instantly with the man at the engines.

At each end of the bridge, and in a line with the chain wheels, there are cast iron sheaves, 3 feet diameter, for the support and guidance of the chains through the bridge; and to prevent the accumulation of sea-weed and mud in the engine-room, the chains are cased off in their passage through the bridge.

Description of the chains, their balance

weights, \&e. XXIII.

The chains are of the common cable pattern, each 1 inch iron, and each link made to a gauge so as to fit the chain wheels without slipping. When the bridge is on either side of the river, the chains lie on its bed, and when the bridge is in the act of crossing, they of course form two ares, as shewn by Plate XIX.

I have before stated, that instead of fixed moorings, the ends of the chains 
are attached to weights suspended in shafts sunk at the heads of the landing places. These shafts are 20 feet deep and 16 feet square, and the weights are cast iron boxes loaded with five tons each, attached to the ends of the chains which enter the shafts over cast iron sheaves, 2 feet diameter, as shewn on Plate XIX.

Now it will be evident that when the bridge is at or near the middle of the river the chains form a double curve, and require to be longer than when the bridge is on either shore and they form but one curve, that is, rest on the bed of the river throughout. Supposing the chains to be fixed to the shore, it is, therefore, manifest that either they must be so short as to be unnecessarily strained, or so long as to allow the bridge to make lee way, and lie uncomfortably at the landing places. But by the plan of the balance weights here adopted, these difficulties are avoided, for as the bridge leaves the one shore the weights then rise, and the chains consequently lengthen to adjust themselves to an easy curve, and as it approaches the other shore, the balance weights on that side fall, the chains are gathered in or shortened, and the drawbridges thereby brought fair and end on to the landing plane; and, which is of the utmost importance, the chains have by this simple contrivance an uniform tension corresponding to the weight assigned to them, and which may be regulated at pleasure.

In the case under consideration, the weights rise and fall from 5 to 8 feet in each shaft, according as the weather and tide may happen.

Nature and extent of accommodation which the bridge af
fords.
It will be obvious from the descriptions already given, as well as from the accompanying drawings, that carriages and traffic of all kinds have a facility for entrance and exit from the roadways or decks of this kind of floating bridge infinitely greater than by any other plan now in use, whilst, from the simplicity of the landing-place, its easy slope, and direct or straight road from thence to and from the roadways of the bridge, carriages with six horses can drive on or off without even the removal of a horse or a passenger.

By the great breadth of the bridge its stability in the water is insured, and it is a rare thing to have even a sufficient degree of motion to attract the attention of the shyest horse, although, as before stated, the situation is so exposed that the ships of war, which lie in ordinary on each side of the site, frequently drag their moorings. 
By employing chains as a guide from shore to shore, the passage by the bridge is rendered safe by night as well as by day, and in rough weather as well as fine; whilst, by the employment of them as a medium through which motion is conveyed to the bridge, a command is obtained over the motion which enables the man at the engine to start, stop, and move forward or back, with a facility and rapidity that could not be obtained by any other means. These advantages are found of the utmost value in the approach to and departure from the landing-places, the chains acting better than any warps, and superseding all necessity for men to attend that operation, as well as for a crew, such as steersman, look-out man, \&c., \&c., there being only two persons necessary for the working of this kind of bridge, viz., the man at the engine, and the man in charge of the drawbridges, and to direct the engine-man when to stop, and start. I have before stated, that the speed at which the bridge is worked across the river is, on an average, 320 feet per minute. This might be considerably increased if necessary, though I do not think it capable of being made equal to the speed of ordinary steam-boats worked by paddles. Still it must not be lost sight of, that in this, as in every other case of travelling, the proper measure for speed is the time taken to perform the journey, or as applied to the instance of crossing a river, the time which is occupied in the passage from the embarking at one shore to the disembarking at the other. Now, by the employment of chains the course is direct, the speed uniform, and may be maintained with safety to the shore approached; and the delay of backing, warping, \&c., \&c., which, on some ferries, takes as much time as crossing the river, is entirely got rid of.

In illustration of this, I need only mention, that the time occupied in crossing by this bridge is 7 minutes at low water, and 8 minutes at high water, (which is 320 feet per minute, the width at high water, as before stated, being 2550 feet,) the time being uniform, whether in rough or fair weather, night or day.

By the double roadway separated by the engine-house, \&c., an opportunity is afforded for the separation of cattle, sheep, pigs, \&c., from carriages and foot passengers.

As a criterion by which to judge of the capabilities of the bridge for accommodation, I would state, that I have seen in it at one time three carriages, each with four horses, one carriage with a pair of horses, seven saddle-horses, and 60 
foot passengers, and still there was nothing like crowding or discomfort. Though the exposure of the site is such that the sea frequently breaks over the funnel of the engines, I have never yet known the passengers of the Devonport and Falmouth mail, or of the other coaches, which regularly cross it twice a-day, leave their seats, even from the top of the coach. Of course, in such cases, the roadway on the lee side is chiefly used.

The bridge crosses the river four times an hour, viz., it leaves Regulations and
government of the bridge. the landing-place on the east side at the half-hours, and the landing-place on the west side at the intervening quarters. The time of crossing, as before stated, is, on an average of high and low water, $7 \frac{1}{2}$ minutes, and therefore the stoppage on each landing-place is $7 \frac{1}{2}$ minutes, making up the quarter of an hour.

The hours of working are from 6 till 10 o'clock in the summer, and from 7 till 9 in the winter, but the Directors allow the public the accommodation of all the intermediate hours on payment of additional tolls and proper notice.

The tolls are let to a yearly tenant free of all expenses except collection, on the covenant that the bridge shall work agreeably to the regulations and hours before described; and for his own interest, the tenant enforces from the servants of the Company the rigid performance of the regulations by ringing the toll-house bell for the starting of the bridge from each side.

During the four years that this bridge has been established, it has not been interrupted in its regular course of working for an hour at any one time, and even that not more than twice or three times, although in this period, as is well known, we have had two very rough winters. We have also had two or three breakages of the chains from defective welds; these, however, only occasioned the delay of a few minutes, as the plan is to continue working on one chain till night, when in the space of an hour the broken ends can be picked up by a grapnel from the bridge and shackled together.

It has never happened that these bridges have broken adrift by the separation of both chains at the same time; and hence will be seen the propriety of using two chains in all cases, each chain being sufficient to hold the bridge.

I cannot, perhaps, give more satisfactory evidence as to the safety, convenience, and fitness of these bridges for crossing estuaries where a fixed bridge cannot be obtained, than by referring to the examination of George Louis, Esq., 
the superintendent of mail coaches, before the committee of the House of Commons which sat on the Post Office affairs in the session of 1835 and 1836 . After pointing out the advantages of such a bridge over the Severn at either the new or old passage, and mentioning the safety and regularity of the one established at Torpoint, he says, "If such a bridge could be made across the Severn, it would render the passage sure."

Expenditure or cost
of the works, dis. I should premise that there are two bridges which work,

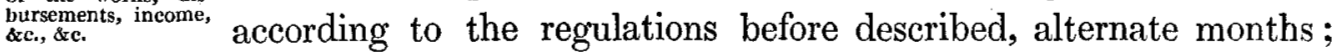
each bridge has its own chains, and they are fitted to be perfectly independent of each other. The advantages of this arrangement will be obvious, affording as it does the opportunity for periodical examination and timely repair, as well as the ready means of providing against the interruption of the traffic by reason of breakage of machinery or accident to the bridge for the time in work. It is also found to be economical, as the interest on the additional capital is more than saved by the facility afforded for repairs, and the diminished wear and tear arising from a regular examination of, and immediate attention to, trifling and incidental derangements in the machinery, \&c.

During the first two years there was but one bridge; and a comparison of the disbursements then with those of the last two years, or since the second bridge has been established, enables me to speak from facts on this point.

The cost of the first bridge, with its machinery and chains, was $£ 3222$; that of the second was $\& 3316$. The cost of the landing planes, shafts, and

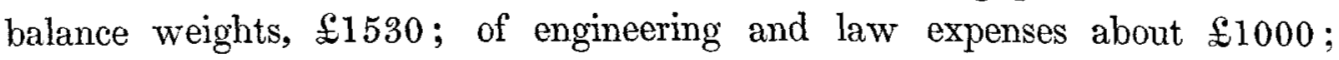
making the whole expenditure about $\mathfrak{E} 9068$. The yearly charges or disbursements are as follow;

WAGES.

Chief engine man $31 s .6 d$. per week, per annum $\begin{array}{llllll}£ & s . & d . & \mathfrak{E} & \text { s. } & d .\end{array}$ Assistant ditto, 25s. per week, per annum

Man to attend to drawbridges and roadways of bridge at $20 \mathrm{~s}$. per week 6500 $\begin{array}{lll}52 & 0 & 0\end{array}$

Two men as occasional labourers in smith's shops, and to assist engine men in the repairs, get coals on board, light lamps, \&c., each $12 s$. per week 6280 


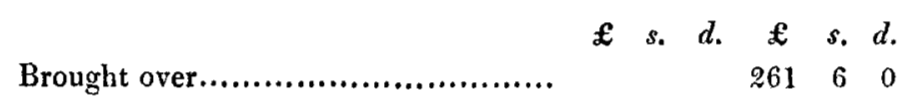

\section{FUEL, ETC.}

The consumption of coals for the year ending Christmas last was 308 tons, (or rather more than $16 \frac{1}{2} \mathrm{cwt}_{\text {. a day, }}$ ) the average price of which in the store was $18 s .6 d$. per ton, or ............................ 284 $18 \quad 0$

Oil for machinery and lamps, tallow, hemp, \&c., \&c., per annum........ $28 \quad 12 \quad 0$

\section{REPAIRS.}

Three sets of cast iron segments for chain wheels, weighing 26 cwt., or the three sets $78 \mathrm{cwt}$., at $14 s$., fitted $54 \quad 12 \quad 0$

$\begin{array}{llllll}\text { Two sets and a half of fire bars a year, or in all } 22 \frac{1}{2} \mathrm{ewt} . \text {, at } 9 s . . . . . . . . & 10 & 2 & 6\end{array}$

Incidental repairs for the year ending Christmas 1837, being for painting, carpenter's work, iron and brass work, and labour, beyond that performed by the servants of the company, and included in account for wages

CREDITOR.

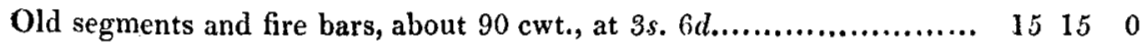

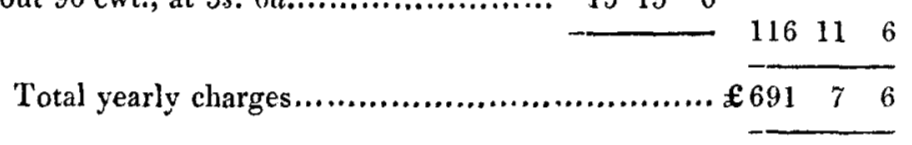

As yet we have no means of fixing with any precision the sum which should be reserved yearly as a rebuilding fund, for the bridges and machinery are still as good as new, and the chains, which at first I expected from the great depth of the river would be an expensive item in the repairs, are scarcely at all worn.

The income of the ferry for the year ending 11th April, 1834, when the bridge was opened to the public, was $£ 930$, whilst for the year now just ending the tolls are let at $\$ 2000$ over and above the cost of collecting, being an increase in four years of $\$ 10 \% 0$, that is, the tolls have already more than doubled. This is the strongest evidence than can be adduced in proof of the great accommodation which the bridge affords.

To have gone into the particular construction and arrangeGeneral and conment of the machinery and scantling of the framing of the bridge, would have extended this paper to a great length, and it would also vOL. II.

G G 
have rendered many plates of illustrative drawings necessary. This being the case, I thought it better to reserve such details for another communication, should it be desired, than to be brief where brevity might only lead to error, for I need hardly remark to the practical engineer, that nothing is more calculated to mislead than incomplete detailed drawings, \&c., of machinery and engine work.

Local circumstances would also so often interfere to modify the details of such a work, that after all, they must be in a great measure left to the judgment of the engineer.

It may be thought that I should have contrasted this kind of floating bridge with the swing bridges, boat bridges, \&c., \&c., of the continent, and with the steam boats employed on some of the great ferries of our own island, but 1 felt that I might have subjected myself to the charge of blind partiality, so often applied, and frequently with justice, to inventors. I therefore intentionally refrain from such comparisons, deeming them less necessary from the circumstance that the members of the Institution, for which this communication is designed, will be the best discerners of the comparative merits of these several plans, as well as of the claims of the one here described to the rank of a useful invention, in a country like ours, having numerous estuaries and narrow seas, where the importance of the navigation or the great first cost will not admit of a fixed bridge, though the population of the district and general traffic of the country suffer from the want of a better communication than ordinary ferries can afford.

In conclusion, I have only further to state, that whilst the bridge here described was in construction, one was established at Saltash, (higher up the Tamar,) and still more recently, a similar bridge (though differing in the arrangement of its details to suit the locality) has been established under my directions at Southampton, across the Itchen, which is, at the site of the bridge, 1400 feet wide at high water, and is crossed 8 times an hour. This bridge is found so formidable a rival to the fixed bridge a little higher up the same river at Northham, as to have drawn off nearly all the travelling, the trifling saving in distance into the Portsmouth, \&c., road which the floating bridge and new road effect, being sufficient to induce all the stage-coaches and mails, amounting to 11 a day, and general travelling, to use it in preference. This is the most convincing proof that the accommodation is regular and commodious. Already 
the tolls of this bridge have been let for $\$ 2500$ per annum, although the work has not been finished 18 months, and the only traffic on the ferry previously to the establishment of the bridge was foot passengers, and produced only $\mathfrak{L} 400$ a year.

JAMES M. RENDEL.

34, Great George Street, Westminster, Feb. 1838.

G $\mathbf{G} 2$ 


\section{PIAN OF THE FAMOAZE,}

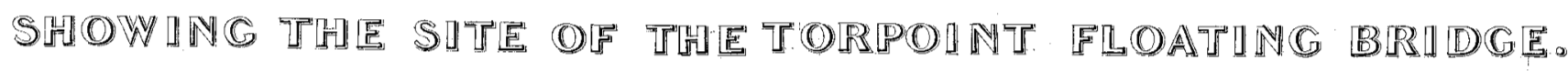

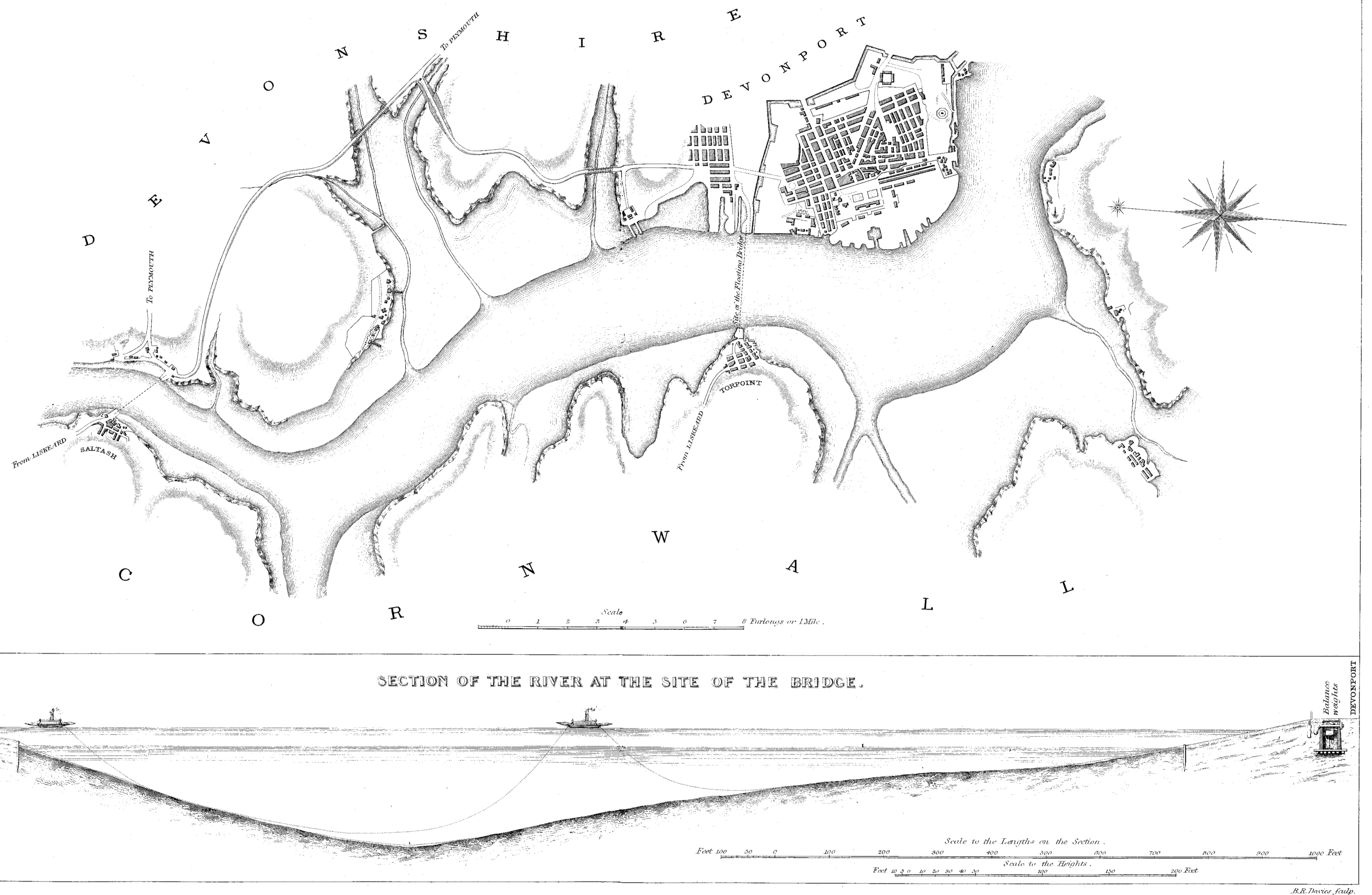



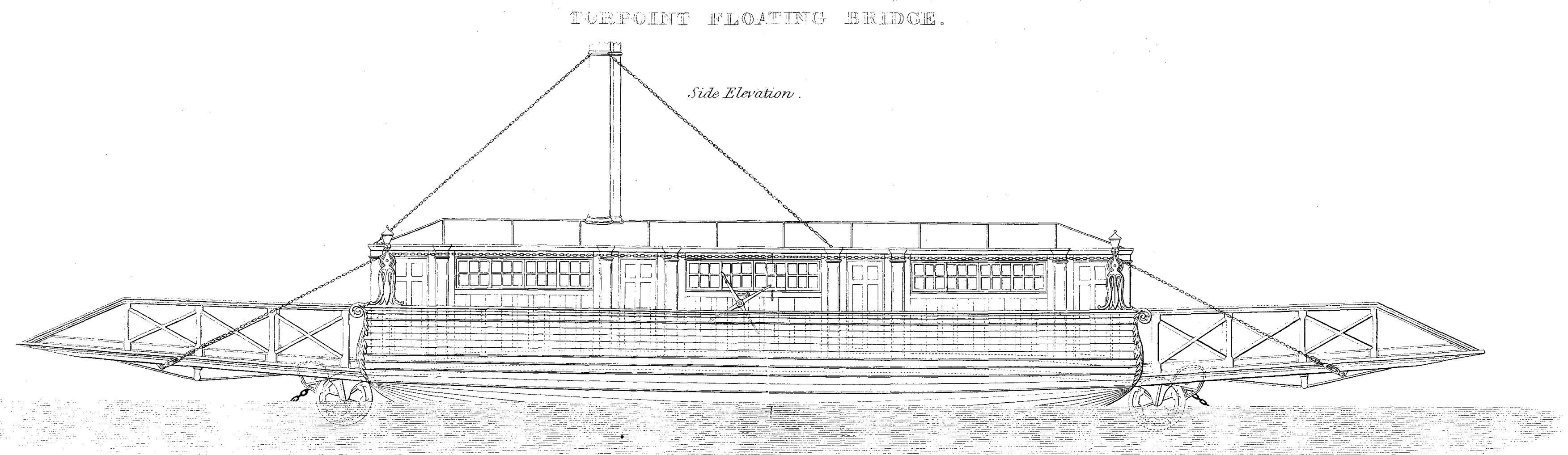

Plan
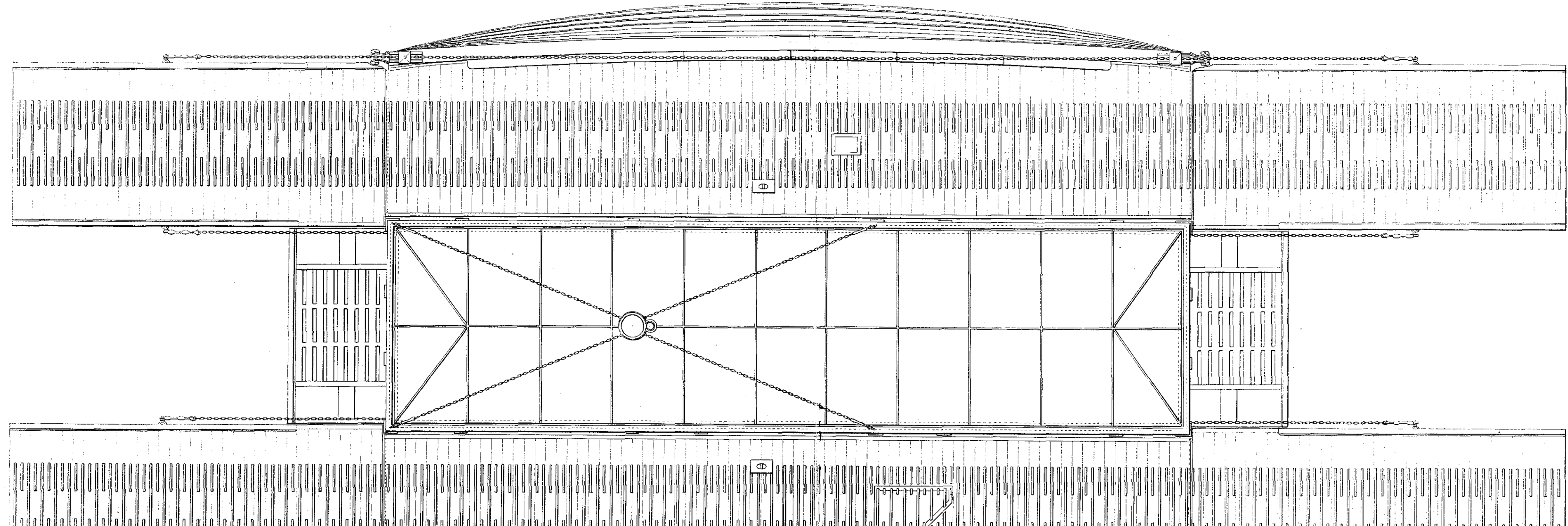

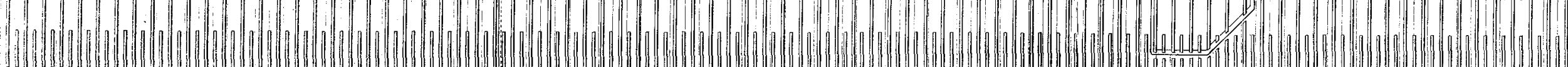

U.

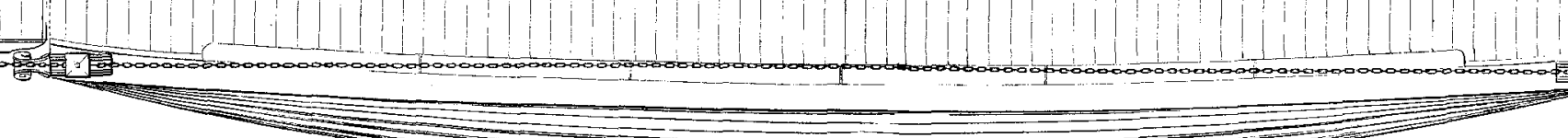




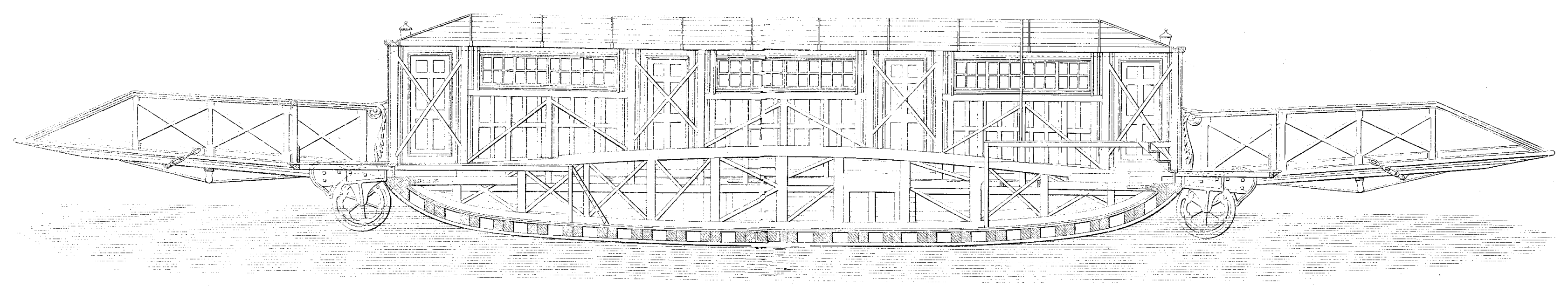

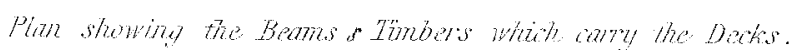

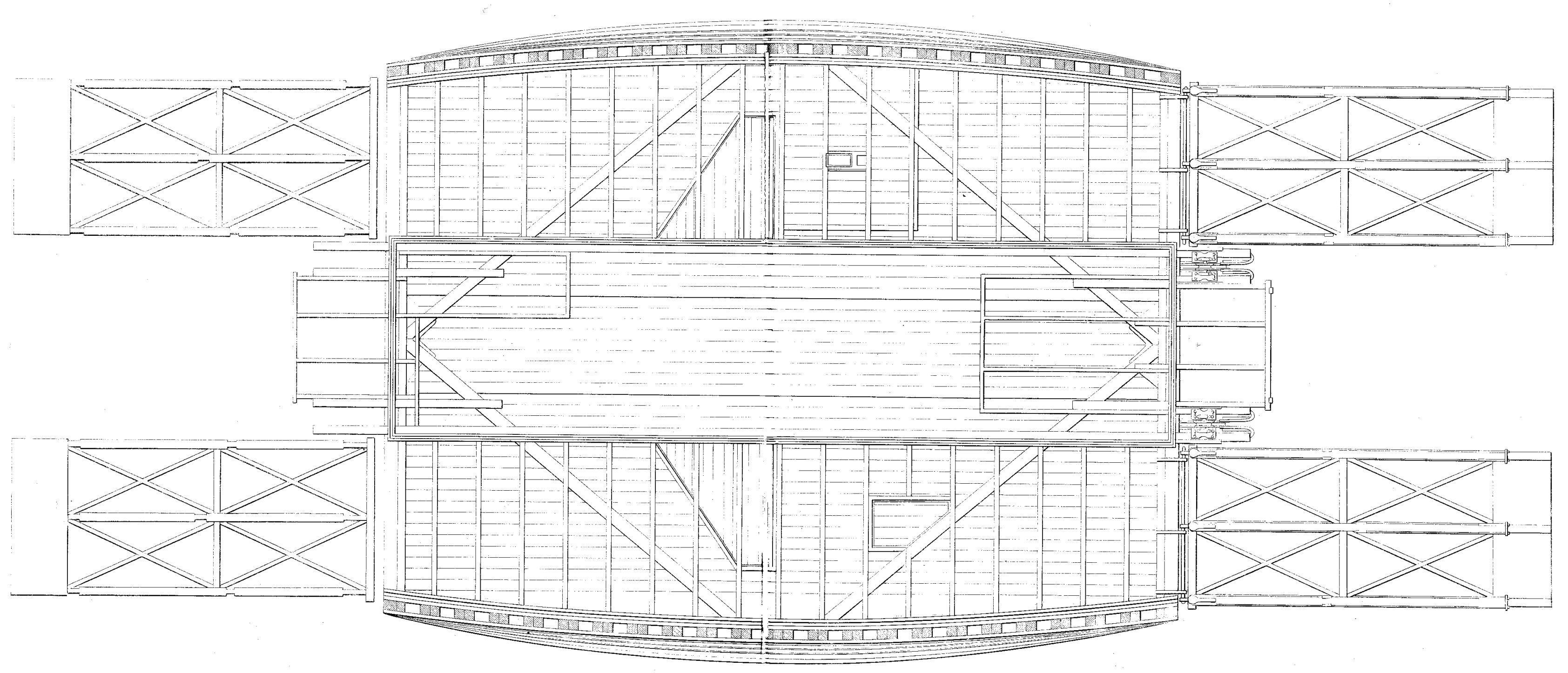




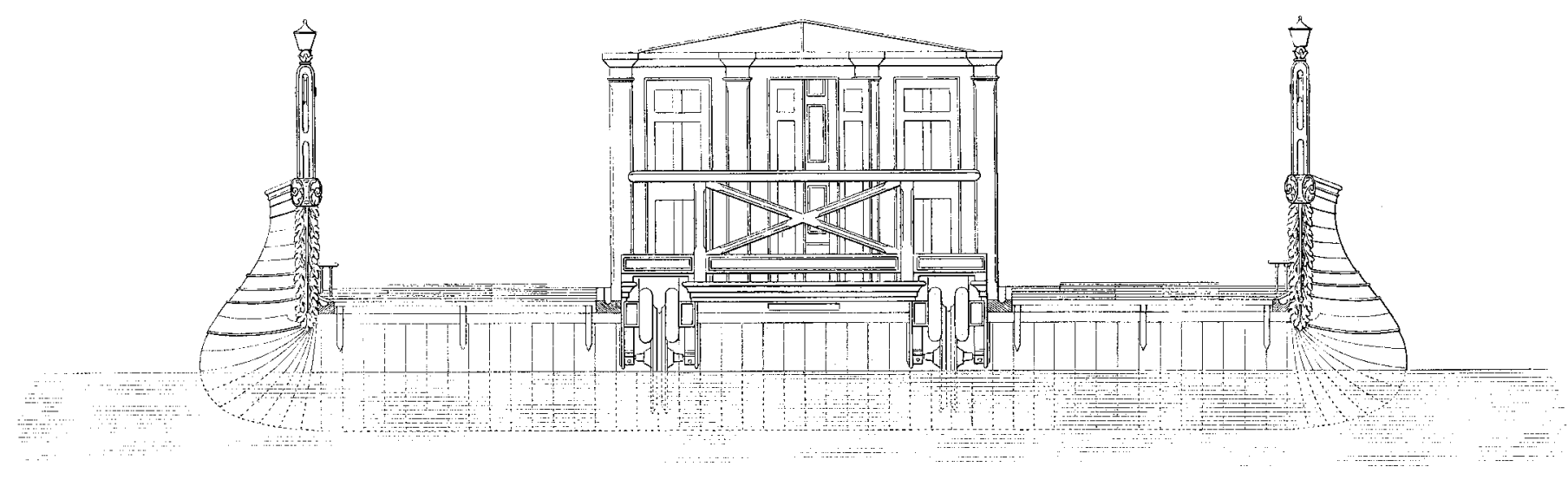

Thansverse Section through the Centre.
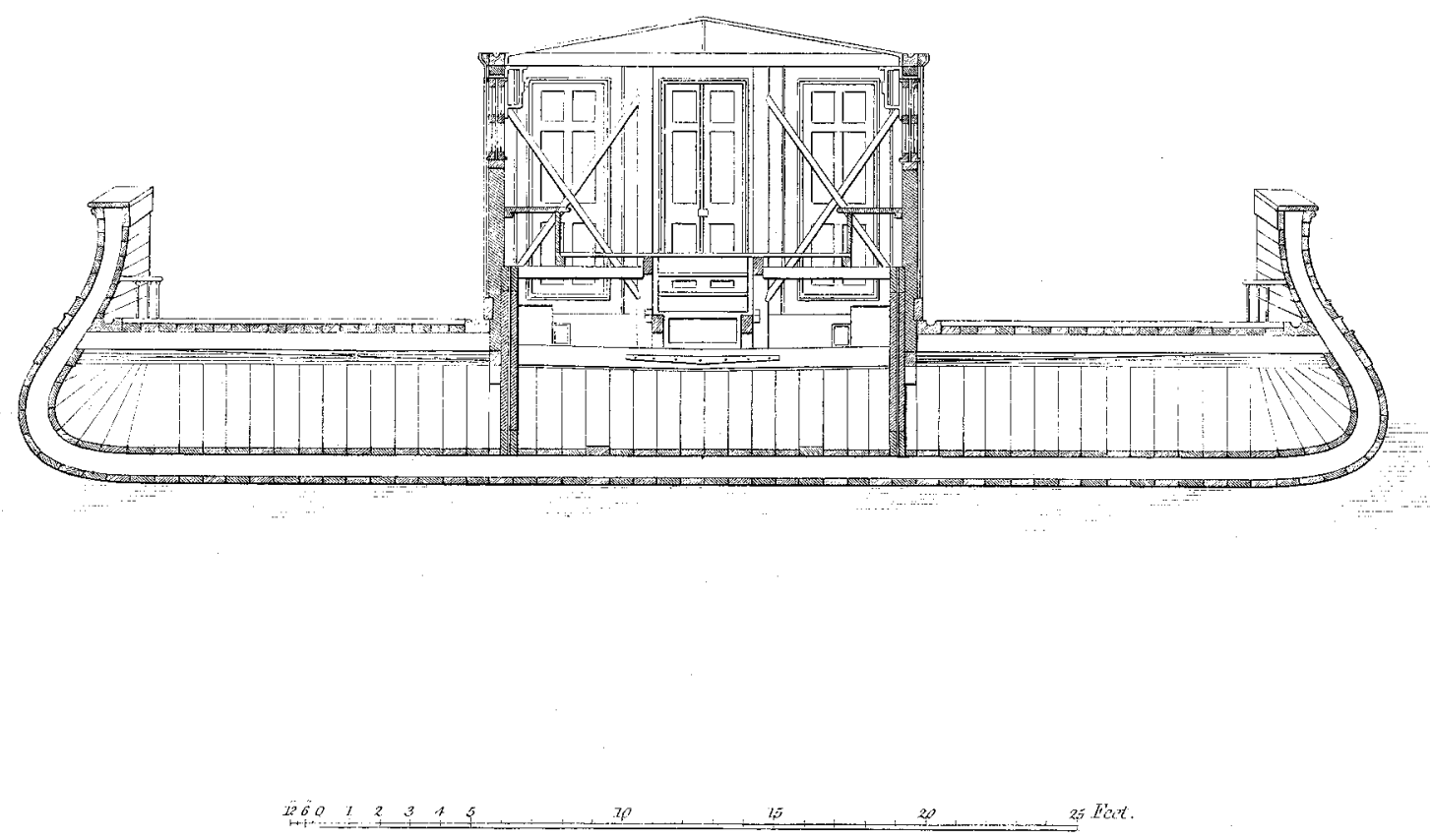


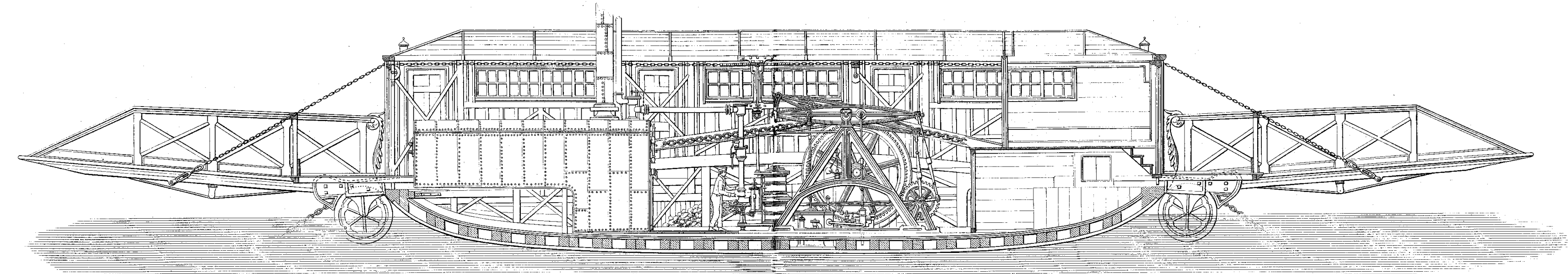

Plan showing the Machinery.

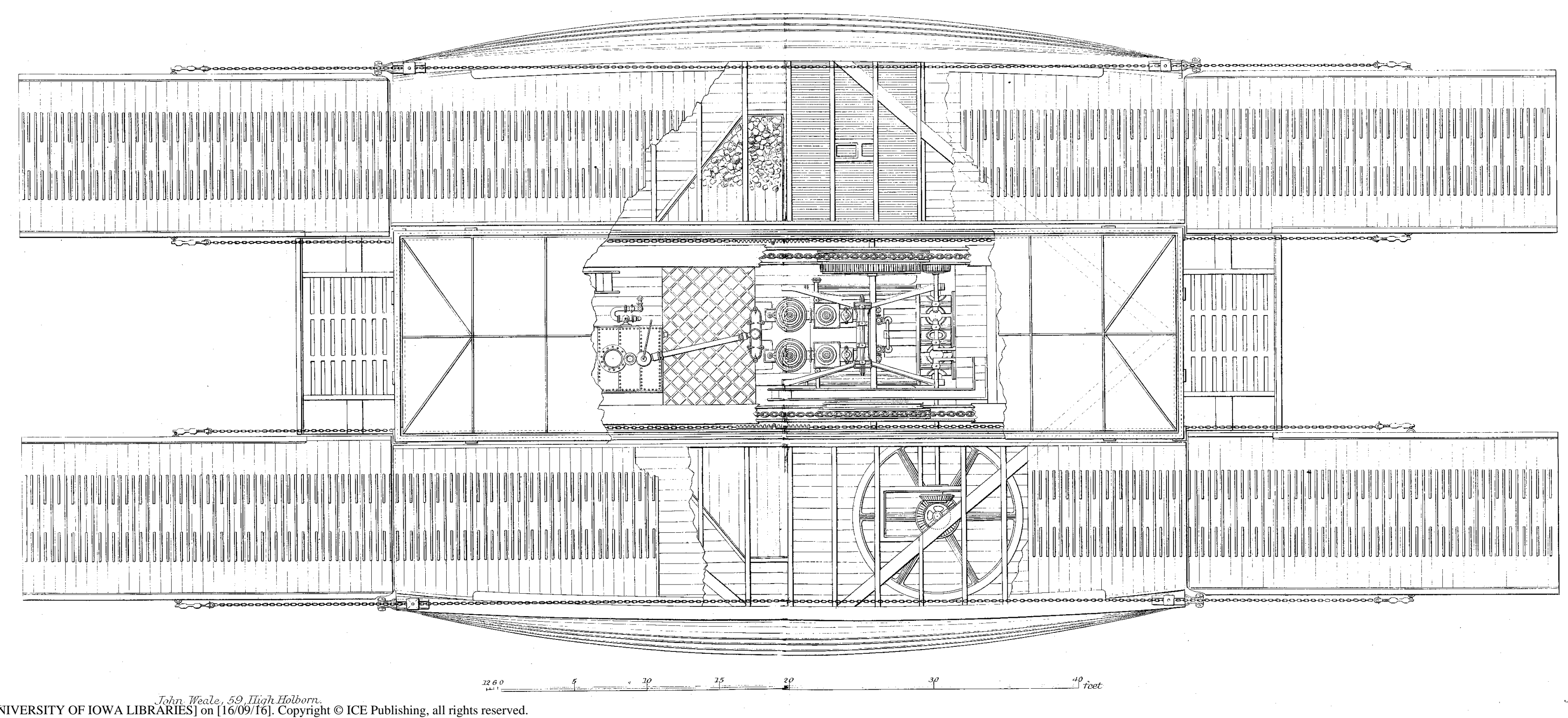

